\title{
1. Creative work beyond the Creative Industries: an introduction
}

\section{Greg Hearn, Ruth Bridgstock, Ben Goldsmith and Jess Rodgers}

Creative occupations exist across the entire economy. The creative worker's habitus cannot be discovered by looking only in film studios, games companies or artists' garrets. Work practices, evolved through the traditions of the creative and performing arts, are now deployed to create new services and products across all sectors, to develop process innovations, and to change the distribution thereof. Yet the bulk of academic study of creative work (both functionalist and critical), as well as the content of higher/ further professional education programs and everyday understanding of creative workers, focuses on one subset of the Creative Industries: those involved in the production of cultural goods or services (film, television, music etc.) for consumption by the general public. And further, the bulk of existing academic work focuses on those creative workers employed in Cultural Production industries. However, as recent work has shown, this focus misses both the large (and increasing) number of creative workers embedded in industries beyond the core Creative Industries (for example, manufacturing, banking, mining) and those creative workers and firms that supply services to business as well as to the general public, such as architects, technical writers and graphic designers (see Cunningham 2013; Potts and Cunningham 2008; Potts et al. 2008). This book focuses on this subset of very important, and yet under-recognized creative workers: embedded creative workers and providers of Creative Services into other sectors of the economy, as indicated in taxonomy shown in Table 1.1, which juxtaposes occupation and industry sector.

The first point to note in examining Table 1.1 is a simple one: the difference between 'an industry sector', defined in aggregate by its outputs measured via assessment of firms' outputs, and 'an occupation', defined by the work of individuals and measured via descriptions of that work. While the semantic descriptions of some industries and occupations may align (for example, film or marketing), 'industry' and 'occupation' are 
Table 1.1 The focus of this volume

\begin{tabular}{lll}
\hline & $\begin{array}{l}\text { Cultural Production } \\
\text { occupations }\end{array}$ & $\begin{array}{l}\text { Creative Services } \\
\text { occupations }\end{array}$ \\
\hline Creative Industries & Specialist Cultural & Specialist Creative \\
& Production workers & Services workers \\
Other industries & Embedded Cultural & Embedded Creative \\
& Production workers & Services workers \\
\hline
\end{tabular}

of course two distinct concepts, which are empirically separable. In line with the work of the Australian Research Council Centre of Excellence for Creative Industries and Innovation (hereafter CCI), we define the Creative Industries as consisting of: architecture, design and visual arts; music and the performing arts; film, radio and television; writing and publishing; advertising and marketing; and software and digital content. Occupational segments can be similarly classified. The term 'Creative Industries' can be segmented into two sub-categories, namely, 'Cultural Production' and 'Creative Services'. We use this terminology in relation to occupation in Table 1.1. The segments that define the terms 'Cultural Production' and 'Creative Services' are depicted in Table 1.2. The occupations in each of the segments are listed in Table 1.3.

The range of chapters showcased in this volume covers the neglected quadrants: those not concerned with producing cultural artefacts for consumption (movies, books, films, computer games, news content) and those that capture creative occupations and work practices used for other purposes. This includes Cultural Production workers and Creative Services workers embedded in other industries, as well as creative work in Creative Services firms who are contracted to other industries. We justify this focus not only because these occupations and work practices have been relatively neglected in academic studies, but also because there are

\section{Table 1.2 Cultural Production and Creative Services segments}

\begin{tabular}{ll}
\hline Cultural Production segments & Creative Services segments \\
\hline Film, TV and Radio & Advertising and Marketing \\
Music, Visual and Performing Arts & Architecture and Design \\
Publishing & Software and Digital Content \\
\hline
\end{tabular}

Note: The architecture, design and visual arts sub-sector was split between the segments, with architecture and design going to Creative Services and visual arts to Cultural Production. 
Table 1.3 Creative occupations by industry sectors under the Australian and New Zealand Standard Classification of Occupations ( $A N Z S C O)$

\begin{tabular}{|c|c|}
\hline Creative occupation ANZSCO & Creative segment \\
\hline Media Producer (excluding Video) & Film, TV \& Radio \\
\hline Radio Presenter & Film, TV \& Radio \\
\hline Television Presenter & Film, TV \& Radio \\
\hline Art Director (Film, Television or Stage) & Film, TV \& Radio \\
\hline Director (Film, Television, Radio or Stage & Film, TV \& Radio \\
\hline Film \& Video Editor & Film, TV \& Radio \\
\hline Technical Director & Film, TV \& Radio \\
\hline $\begin{array}{l}\text { Film, Television, Radio \& Stage } \\
\text { Directors nec }\end{array}$ & Film, TV \& Radio \\
\hline Television Journalist & Film, TV \& Radio \\
\hline $\begin{array}{l}\text { Camera Operator (Film, Television or } \\
\text { Video) }\end{array}$ & Film, TV \& Radio \\
\hline $\begin{array}{l}\text { Production Assistant (Film, Television, } \\
\text { Radio or Stage) }\end{array}$ & Film, TV \& Radio \\
\hline Arts Administrator or Manager & Music \& Performing Arts \\
\hline Actor & Music \& Performing Arts \\
\hline Dancer or Choreographer & Music \& Performing Arts \\
\hline Entertainer or Variety Artist & Music \& Performing Arts \\
\hline Actors, Dancers \& other entertainers nec & Music \& Performing Arts \\
\hline Musician (Instrumental) & Music \& Performing Arts \\
\hline Singer & Music \& Performing Arts \\
\hline Light Technician & Music \& Performing Arts \\
\hline Make-up Artist & Music \& Performing Arts \\
\hline Sound Technician & Music \& Performing Arts \\
\hline Performing Arts Technicians nec & Music \& Performing Arts \\
\hline Book or Script Editor & Publishing \\
\hline Newspaper or Periodical Editor & Publishing \\
\hline Print Journalist & Publishing \\
\hline Technical Writer & Publishing \\
\hline Journalists \& other writers nec & Publishing \\
\hline Librarian & Publishing \\
\hline Library Technician & Publishing \\
\hline Library Assistant & Publishing \\
\hline Proofreader & Publishing \\
\hline Photographer & Architecture, Design \& Visual Arts \\
\hline Painter (Visual Arts) & Architecture, Design \& Visual Arts \\
\hline Architect & Architecture, Design \& Visual Arts \\
\hline Landscape Architect & Architecture, Design \& Visual Arts \\
\hline Fashion Designer & Architecture, Design \& Visual Arts \\
\hline
\end{tabular}


Table 1.3 (continued)

\begin{tabular}{ll}
\hline Creative occupation ANZSCO & Creative segment \\
\hline Industrial Designer & Architecture, Design \& Visual Arts \\
Graphic Designer & Architecture, Design \& Visual Arts \\
Interior Designer & Architecture, Design \& Visual Arts \\
Urban \& Regional Planner & Architecture, Design \& Visual Arts \\
Architectural Draftsperson & Architecture, Design \& Visual Arts \\
Jeweller & Architecture, Design \& Visual Arts \\
Advertising \& Public Relations Manager & Advertising \& Marketing \\
Marketing Specialist & Advertising \& Marketing \\
Advertising Specialist & Advertising \& Marketing \\
Copywriter & Advertising \& Marketing \\
Web Designer & Software \& Digital Content \\
ICT Business Analyst & Software \& Digital Content \\
Systems Analyst & Software \& Digital Content \\
Web Developer & Software \& Digital Content \\
Analyst Programmer & Software \& Digital Content \\
Developer Programmer & Software \& Digital Content \\
Software Engineer & Software \& Digital Content \\
Software \& Applications Programmers nec & Software \& Digital Content \\
ICT Quality Assurance Engineer & Software \& Digital Content \\
ICT Systems Test Engineer & Software \& Digital Content \\
Web Administrator & Software \& Digital Content \\
\hline
\end{tabular}

Note: $\quad$ nec $=$ not elsewhere classified.

Source: Andrews, Yeabsley and Higgs (2009).

about four times as many creative workers across these quadrants as in the core Cultural Production sector alone. Moreover, with some exceptions, employment outside the Cultural Production sector is growing more strongly than within it, particularly in Creative Services. There are theoretical reasons for this focus as well. One important reason is that the context, conditions, contributions and education of creative labour cannot be fully understood by referring only to the Cultural Production sector. Another is that the dynamics of innovation in contemporary economies cannot be understood as deriving only from science and technology, but rather must include an understanding of the role played by those creative occupations that are engaged industrially.

The pursuit of this agenda has primarily been possible because of the detailed empirical apparatus established by the CCI, based on census statistics in Australia, the UK and New Zealand. The original intention of 
the examination of census data was to analyse the economic fundamentals of the Creative Industries, in terms of the size and growth of their contribution to gross domestic product (GDP). This task proved very difficult because of outdated industry classifications, which resulted in the need to disaggregate some sectors, such as computing services, which encompassed the emerging fields of games and web design. Researchers in CCI (see, for example, Cunningham and Higgs 2009) hit on the idea of using occupational data (ANZSCO or Standard Occupation Classification) as a proxy for the size of these sub-sectors, because occupational data provide much more fine-grained accounts of creative work than do industry data. It was this primary insight that led to the finding that there were more creative workers outside the Creative Industries than within them.

As a result of this work, we have come to realize that many kinds of theoretical problems can be approached using census data for occupations. These data are rigorously collected, very robust, not subject to sampling errors of primary surveys, and extend the value of ethnographies of creative work. Many of the chapters herein utilize CCI's occupational data approach, or other major databases (such as Household Income Labour Dynamics Australia), or are primary surveys. However, qualitative and theoretical expositions are also represented, and are very important to the task at hand.

The conceptual raison d'etre for the book is a holistic consideration of creative work outside the Creative Industries. However, we were driven by three important debates. First, we wanted to make sense of why this kind of work has emerged in contemporary economies, and why it is growing. Second, we wanted to examine what this new empirical approach had to say about the issues of the precarity of creative labour - a debate largely shaped by considerations of the workers in the Cultural Production sector. Third, we wanted to understand the implications of this approach for the educational preparation and ongoing professional learning of workers in these occupations.

\section{CREATIVITY, CREATIVE WORK AND INNOVATION}

Why does creative work seem to be important to all sectors? At the macro level, there is a considerable amount of writing on the ways in which modern corporations have been shaped by the culturalization of economic life (Lash and Urry 1994). In fact, at least 50 per cent of GDP in modern economies is composed of personal consumption of goods and services. Increasingly this is directed not only towards the pursuit of cultural goods but also to the culturalization of all products and services. For example, 
manufacturing industry products, such as cars or furniture, or financial services, such as home loans or credit facilities are sold as lifestyles. Even health services include cosmetic procedures and aged-care lifestyles.

In addition, it can be argued that all economic activity is 'embedded' in the social sphere (see, for example, Granovetter 2005) and, we would add, that creative occupations are partially the agents of this embedding. That is, economic life depends on various sets of social relationships being enacted effectively, apart from the relationship with the consumer. For example, social networks play a key role in labour markets in terms of transmitting information about employers, employees and job flows. Many tasks in any value chain require serious cooperation from others. We suggest that digital media now facilitates these relationships - and creative digital workers are foremost in creating this infrastructure of embedding'. For example, Mudambi (2008) and Hearn and Rooney (2008) argue that there is creative input along the value chain in many sectors. This includes the use of design disciplines to capture value at the beginning of the value chain, and the use of digital and media disciplines at the end of the value chain to attempt to control the relationship with consumers via branding, advertising and, now, social media. Dell'Era et al. (2011) argue that designers are implicated throughout the product cycle. Designers may be involved in designing functionality, changing the meaning of a design, or creating new categories of product.

Stoneman's (2010) notion of 'soft innovation' also suggests why we might find the embedding of creative occupations throughout the economy. He proposes that the kind of innovation found in the Creative Industries is different from technical R\&D (see also Bakhshi, Hargreaves and Mateos-Garcia 2013, 51-62; Cunningham 2013). Essentially soft innovation refers to aesthetic changes that are nevertheless economically important, including in sectors beyond the core Creative Industries. $\mathrm{He}$ offers the food industry and pharmaceutical industry, for instance, as sectors where aesthetic branding plays a part.

Cunningham (2013) and his collaborators (see, for example, Potts and Cunningham 2008; Potts et al. 2008) make a stronger case for the role of the creative sector in producing innovation across the economy as a whole. Cunningham (2013) suggests that creative sector innovation is not just aesthetic variation, but more intrinsic, particularly in the case of design. Potts and Cunningham (2008) go further, arguing that the growth in the Creative Industries is correlated with rising affluence, more specialized and larger stocks of human capital, the rise of ICT (information and communication technology) and globalization. Moreover, they propose that the Creative Industries are implicated in the growth of the whole economy. Beyond the adoption of new ideas and technologies, they may in fact be 
the engine of the higher-order cultural novelty driving economic evolution, and have led to steep changes in economic activity, such as the widespread adoption of the Internet, or the design-led innovation movement.

Although the testing of theory has not yet caught up with the empirical reality of embedded creative workers (Hearn and Bridgstock 2014), the ideas discussed above suggest that it is reasonable to look to their role in innovation as an explanation for this phenomenon. The next question the current volume asks is: if these workers are important to the process of innovation, are they rewarded commensurately in terms of their conditions and remuneration?

\section{PRECARITY AND EMBEDDED CREATIVE LABOUR}

Recent research has indicated that the labour conditions and experiences of the creative workforce in general have a number of distinct characteristics (Cunningham 2011). Most creative workers, it is argued, are contract labourers rather than permanent employees, are highly mobile in their place of employment, will typically experience 'portfolio careers' or multiple career pathways, and are less likely than in the past to be employed and trained through large, often public sector, agencies. At the same time, most creative employment has been found to occur outside the core Creative Industries, with design occupations in particular in demand outside the specialist design industry sectors.

In their analysis of creative labour in the publishing, music and television industries, Hesmondhalgh and Baker (2011) outline the 'remarkable fact' of the virtual absence until relatively recently of a focus on creative labour in studies of Cultural Production across three contrasting research paradigms: political economy of culture; organizational, business and management studies; and cultural studies (ibid., 55). The recent 'turn to labour' in cultural studies, of which Hesmondhalgh and Baker's work forms a part, tends to critique the conditions and experiences of workers in the core Creative Industries. This new focus has been in part a response to 'celebratory' accounts of the economic power of creativity and the Creative Industries that are also argued to have 'strategically ignored . . . the labor dimension essential to creative production' (Pang 2009, 55). The expansion of the Creative Industries, their popularity with policymakers, and the boosterism of commentators and consultants such as Florida (2002), Leadbeater (1999) and Howkins (2001) has, critics argue, contributed to a 'tendency to ignore or, conversely, sugarcoat the precarious employment situations prevalent in the [Creative Industries]' (de Peuter 2011, 418). Critical responses to 'creativity hype' (ibid.) have, therefore, begun to 
emphasize the precarious character of creative labour in the core Creative Industries (Neilson and Rossiter 2008; de Peuter 2011). New work in the emerging field of production studies has highlighted both the creativity and precarity of service workers in the Creative Industries (Mayer 2011). Many of these critiques draw on the autonomist tradition of Marxist labour theory, and in particular on the work of Hardt and Negri (2000), to position creative labour as the epitome of transformations of work in advanced economies 'away from stable notions of "career" to more informal, insecure and discontinuous employment' (Gill and Pratt 2008, 2). As Gill and Pratt relate, a variety of recent studies (see, for example, Banks 2010; Christopherson 2008; Hesmondhalgh and Baker 2011; Ross 2008; Pang 2009; de Peuter 2011) have highlighted a number of relatively stable features of [creative] work:

a preponderance of temporary, intermittent and precarious jobs; long hours and bulimic patterns of working; the collapse or erasure of the boundaries between work and play; poor pay; high levels of mobility; passionate attachment to the work and to the identity of creative labourer (e.g. web designer, artist, fashion designer); an attitudinal mindset that is a blend of bohemianism and entrepreneurialism; informal work environments and distinctive forms of sociality; and profound experiences of insecurity and anxiety about finding work, earning enough money and 'keeping up' in rapidly changing fields. (Gill and Pratt 2008, 14)

But these studies, like almost all studies of creative labour, have tended to focus solely on the core Creative Industries: media, design, fashion, architecture and so on. While these studies have usefully directed attention to the particular conditions and experiences of creative workers, for the most part they have overlooked creative labour beyond the Creative Industries. This is despite the fact that a number of studies in different countries have shown that more creative workers are employed outside than within the core Creative Industries, and that employment of creative workers 'embedded' in other industries, or providing creative services to other sectors, is growing at a faster rate than employment within the Creative Industries (Pagan, Higgs and Cunningham 2008; Higgs and Freebody 2010; Higgs, Cunningham and Bahkshi 2008). This growth indicates innovation; new uses and applications are being found for creative skills and attributes across the broad range of industry sectors.

Data about embedded creatives produced first by the CCI, and subsequently by others adopting its Creative Trident methodology, contest some of the findings of studies of precarious creative labour. As one of the architects of the Creative Trident methodology, Cunningham, has noted, 'our studies suggest that embedded creatives do not generally 
exhibit the profiles attributed to creative labour by the precarity school of critical media and cultural studies. A great many creatives, we must assume, have managed precarity by working outside the creative industries' (Cunningham 2011, 38). The chapters in this book make important theoretical and empirical contributions to this debate, and help to tease out some of the issues raised both by proponents of the precarity perspective, and by other scholars of the Creative Industries.

\section{EDUCATION FOR CREATIVE OCCUPATIONS}

The education of the creative workforce is relevant to the discussion of innovation, precarity and the Creative Industries. Because the embedded creative workforce is involved in addressing the interaction, translation and synthesis of knowledge between and among scientific/technical, creative/cultural and business/entrepreneurial disciplines, and also between different sub-disciplines within each (for example, between aerospace engineering and astrophysics in the design and construction of new types of radio telescope) (Hearn and Bridgstock 2010), the processes of knowledge translation and synthesis for innovation require a range of high-level capabilities underpinned by transdisciplinarity, social networking capability and creative entrepreneurship. However, unlike domain-specific 'disciplinary' expertise, these creative workforce skills have yet to find general recognition and acceptance in higher and professional education (Hearn and Bridgstock 2010; Bridgstock and Hearn 2012). Educational approaches to the development of these skills also remain underconceptualized and underdeveloped. Traditional classroom or studio-based pedagogies tend to emphasize the skills required for performance in specialist and unidisciplinary creative work situations, rather than addressing the complex and varied requirements of transdisciplinary embedded and business-to-business services creative work.

A number of skilling, education and training implications also arise from the distinctiveness of creative labour. Labour oversupply, a well-established phenomenon in creative labour markets, particularly for graduate and entry-level positions (Menger 2006), has been observed to result in overeducation among creative workers. Creative overeducation is suggested to occur because underemployed creatives acquire additional education and training in order to compete more effectively for scarce jobs, resulting in a mismatch between the qualifications needed for a creative position and the credentials of the incumbent. Indeed, some survey-based empirical studies confirm this pattern (for example, Caroleo and Pastore 2011).

The portfolio career and observations about precarity of creative labour 
further suggest that, in general, creative workers must ensure their own skill currency, and take personal responsibility for professional development (MKW 2001). Certainly, there are relatively few professional accreditation bodies or formal skill standards for creative occupations. Post-initial training skills acquisition seems primarily to occur through self-directed learning, via mechanisms such as formal and informal internships, and mentoring (Creative \& Cultural Skills 2010). Creative workers are challenged to be what du Bois-Reymond (2004) calls 'trendsetter learners' (187), who set their own learning agendas in response to, or even in anticipation of, emerging industry and market developments. It is not immediately clear, however, how creative workers become trendsetter learners.

In terms of formal and initial education and training provision for creative occupations, there is significant evidence of skills shortages and gaps, particularly in terms of multiplatform and digital content, intellectual property and commercial acumen (Galloway et al. 2002; Creative \& Cultural Skills 2010; Haukka 2011). In Haukka's (2011) survey of employers of graduates from creative disciplines, almost half reported having difficulty recruiting 'the right skills'. While some mismatches between employer expectations and graduate skills seem inevitable, and while educational institutions will always struggle to keep abreast of the latest digital tools of trade, empirical work suggests that creative graduates are fairly well equipped in terms of core disciplinary and broad generic employability skills (such as written communication, critical thinking and numeracy) (Ball, Pollard and Stanley 2010; Haukka et al. 2010). However, recent research indicates that there is a range of other high-level capabilities that are critical to success in creative work, namely, social network capability, disciplinary agility, enterprise and career self-management (Hearn and Bridgstock 2010; Bridgstock and Hearn 2012; Bridgstock 2013a, 2013b).

While higher and further education are adept at delivering conventional curricula for disciplinary and generic skill development, these four clusters of Creative Economy capabilities have not yet received general recognition and acceptance in post-secondary education (Hearn and Bridgstock 2010). Nor is it entirely clear which pedagogical approaches might prove most effective in developing capabilities, or how to assess for them. Further, while we may speculate how the Creative Economy capabilities required by embedded creative workers may be different from those required by creative workers who operate within the Creative Industries (for example, Hearn and Bridgstock 2014), little empirical work on this topic yet exists. Research may also reveal other capabilities as particularly important to embedded creative workers, or perhaps certain permutations of the creative economy capabilities presented herein will emerge as fundamental to 
the embedded creative worker's skill set. For example, an embedded creative designer might need well-developed enterprise opportunity recognition capability and social network capability in order to identify the most innovative specialist suppliers of design services. Two further questions relating to the education and training of embedded creatives are: how does tertiary education go about preparing students for the likelihood of embeddedness, given that beginning students often aspire strongly to specialist roles? And should there be special professional development and support mechanisms specifically for embedded creatives in different fields?

\section{OVERVIEW}

To pursue the issues raised above, the book is divided into three parts.

Part I explains the importance of creative work outside the Creative Industries and examines the role of this work in innovation. It also extends the precarity debate into the domain of embedded creative work. Part II comprises a series of case studies of embedded creative work and workers in a variety of industries and contexts. These help to identify embedded creative workers, what exactly they do and how they embed into particular industries. Part III examines education, skills and career issues for embedded creatives.

\section{Part I Foundational Issues}

In the opening chapter of Part I, 'Creative labour and its discontents: a reappraisal', Stuart Cunningham provides a broad overview of the theoretical and measurement debates around the phenomenon of creative labour. Cunningham dissects the 'precarity' perspective, a body of cultural studies and labour studies scholarship that has had a particular interest in labour in the arts, cultural and Creative Industries. While acknowledging problems with the overly positive depictions of labour precarity in early commentary on the role of creativity in the modern economy, in particular in the work of writers such as Florida, Leadbeater and Howkins, as well as in his own early writing on the subject, Cunningham provides a number of responses to the criticisms of those writing from the precarity perspective. Cunningham points to the ways in which creative workers manage their precarious labour conditions, highlighting the degree of embeddness in creative occupations as a factor that tends to be ignored in precarity debates. Consequently, Cunningham notes that creative workers arguably face a less precarious future than their counterparts in other sectors, such as agriculture, mining or low-wage service sectors. 
The second part of Cunningham's chapter discusses the development by the CCI (of which Cunningham is the Director) of its Creative Trident methodology for measuring the creative workforce. The Trident methodology divides the creative workforce into 'specialist', 'embedded' and 'service' occupations, and has contributed to substantial improvements in employment statistics and analyses of rates of change in the Creative Industries. The second iteration of the Trident methodology divides creative occupations into 'Cultural Production' and 'Creative Services' groupings, a development that has permitted even more fine-grained analysis of creative employment and the distinctiveness of this workforce. Cunningham's chapter thus provides an important introduction to the various discussions of embedded creative labour and Creative Services provision in the chapters that follow.

Jason Potts and Tarecq Shehadeh utilize the Household Income Labour Dynamics Australia (HILDA) survey panel to examine empirical evidence of the claim that the market for creative labour is precarious. They question the assertion of precarious employment, finding that it is only 'relatively' evident among creatives within Creative Industries and not at all evident among creatives embedded in other industries. The 'relative' precarity appears to be a function more of the industry, rather than occupational classification, and not systemic to creative employment as a whole. The data also reveal the significant variety of non-monetary compensating factors working to affect the relative desirability of work within the creative sector, such that precarity might actually be a dimension against which other terms of compensation are traded. The authors conclude that when these compensating differentials are factored in, employment in either Creative Industries and/or occupations is, in aggregate, neither better nor worse than employment in other sectors.

The next chapter by Dan Swan and Greg Hearn continues the focus on creative workers who are deploying their capacities in other sectors outside their core industry, through the contracting of Creative Services. They argue that one reason for the growth in creative digital services in particular, in relation to other industries, is that they are drivers of innovation. They present three case studies where creative digital services firms were deployed in companies in other sectors, namely, mining, education and manufacturing. They suggest that the integration of creative components into services or products in other sectors is not straightforward, and not always successful. The need to understand what makes a creative intervention 'interoperable' with products or services in other industries is a major finding of this chapter. Two processes arguably underlie this collaborative process. First, brokering was necessary for partnerships between host and digital creative firm to occur. In the subsequent embed- 
ded phases of discovery and incubation it was the bridging of knowledge systems that was then necessary for successful innovation. This raises important questions surrounding the nature and systems of shared language required for embedded creative digital knowledge. The evaluation of the case studies suggested that, without the intervention of programs that enable brokering and bridging, organizations struggle to engage the knowledge provided by creative digital companies in order to produce valuable creative outcomes.

Alan Freeman's discussion of London's creative workforce concludes Part I. Freeman opens his chapter with the example of the establishment of Nissan's design studio in the heart of London. He provides a valuable overview of the significance of creative occupations to the Creative Economy through a narrative that traces the development of researching London's Creative Industries against a governance and policy backdrop. London, as a world stage of creativity, is a key site for the emergence of Creative Industries policy and measurement. At the emergence of this area of interest there was no workable theory of how the cultural or Creative Economy functioned. For over a decade, research by a number of organizations sought to locate, define and measure the creative workforce in London, where and why it was growing, and where and why it clustered. Most recently the Creative Intensity model of defining creative occupations shifted from a priori taxonomies of industries and occupations to measurement by the characteristics of work (for example, whether the work can be mechanized). The indispensable input provided by such labour is precisely that which could not be replaced - its creativity. This approach found that creative intensity in the Creative Industries is 25 times greater than in the rest of the economy - with intensities ranging from 30 to 80 per cent - and helped to explain creative clustering. The creative intensity of industries is also shown to be a useful way to think about the notion of embedded creatives.

\section{Part II Case Studies of Embedded Creative Employment}

To begin the case study section, Janet Pagan and Jess Rodgers update the 2008 Getting Creative in Healthcare report (Pagan, Higgs and Cunningham) by detailing the changes in embedded creative work in the Australian healthcare industry since the 2006 Census and considering reasons for the shape of creative work in this industry. Embedded creative workers form 0.5 per cent of the healthcare industry. The average for all industries is 1.6 per cent. The Getting Creative in Healthcare report found that creative contributions to healthcare occur in other ways as well, such as through contracted services or contributions from those who have no 
creative training. Between 2006 and 2011, creative employment embedded in healthcare increased at about the same rate as the total healthcare workforce -19 per cent. The overall increase in embedded creative employment was driven by the 34 per cent growth of the largest segment, software and digital content. This chapter considers the types of contributions that the different segments make to healthcare and the industry contexts that influence different levels of creative employment. Primary contributions come from ICT analysts, web and software developers. Pagan and Rodgers also consider the role of allied health therapists who are not counted as creative workers in the Trident methodology.

In Chapter 7, Jess Rodgers examines embedded creatives in the Australian manufacturing industry. Embedded creative employees make up 2 per cent (17635) of manufacturing industry employees. The average for all industries is 1.6 per cent. Given this higher presence of creative workers, the importance of manufacturing to the Australian economy, and the significance of innovation to manufacturing, Rodgers considers how embedded creative workers contribute to innovation in this industry. The architecture and design and advertising and marketing segments house the most embedded creative workers in manufacturing, at 45 per cent and 27 per cent respectively. Rodgers explores, through case study interviews, the type of companies these embedded creatives work for, the types of positions they hold, their contributions to innovation and the challenges they face. The embedded creative workers interviewed bring a variety of value-add propositions to their companies, including translation, reaching customers and product differentiation. However, the interviewees often feel that their creative input is not valued by their companies. Drawing on other research, Rodgers suggests that these experiences are not atypical and makes recommendations for interdisciplinary environments that foster innovation, and Creative Industries education.

In Chapter 8, 'Embedded digital creatives', Ben Goldsmith explores the different ways in which digital creative workers have featured in official reports and studies, and points out that these and other documents tend to display only limited understanding of the role of creative workers in the digital economy and in innovation, the issues they face, and their specific needs. Goldsmith's chapter poses a series of questions: who are digital creative workers? Where are they working? Where are their numbers growing? Using principally Australian Census data, Goldsmith then proposes a typology of digital creative occupations as a means both to estimate the size of the digital creative workforce and to better understand and assist planning for the needs and potential of this increasingly important group. The typology comprises three groups of occupations: 'Born Digital' creative occupations, such as software developers, whose 
work essentially did not exist before the digital age; 'Digital Migrants', such as television presenters, whose occupations existed before digitization but whose creative work is now entirely reliant on digital technologies or processes; and 'Semi-Digital creatives', or occupations in which digital technologies and processes may or may not be used, such as advertising and marketing professionals. These categories are then broken down into the Creative Trident II division between Cultural Production and Creative Services. Goldsmith's findings show that, while there is high growth in both specialist digital Cultural Production and Creative Services occupations, embedded digital creative occupations grew much more slowly. The findings also provide a sounder basis than previously available for estimating the size of both the digital creative workforce as a whole, and that of the specialist and embedded digital creative workforce.

In his second chapter in this volume, 'Embedded digital creative workers and Creative Services in banking', Goldsmith examines creative inputs into the banking industry through the optic of mobile applications (apps) development. Finance industries are particularly fertile ground for the analysis of digital and embedded creative work; in Australia, finance and insurance services industries employ both the highest proportion of embedded creative workers and the largest total number of software and digital content workers. The work of embedded digital creative workers and services provided by specialist creative firms are becoming increasingly important in the finance sector as Internet and mobile banking grows. Banks, in particular, are experiencing customer demand for mobile apps that enable a range of personal and corporate financial services. As Goldsmith demonstrates, this requires the deployment of a variety of digital creative workers in the design and development of innovative models and interfaces, the animation of icons, actions and services, and the development of image-based, graphically rich and user-friendly interfaces. Goldsmith describes the three models of bank apps development, with examples drawn principally from the Australian banking sector. These examples show that, while functionality and convenience are important attributes of financial services apps, so too are aesthetics and user engagement. Sharp growth in the use of mobile services and in the popularity of mobile banking indicates that the role of digital creative workers and specialist creative firms in the banking sector is likely only to grow in coming years.

In Chapter 10, 'Looking inside the portfolio to understand the work of creative workers: a study of creatives in Perth', Dawn Bennett and colleagues report on a survey-based study of the careers, work practices and skill needs of professional creatives in Perth, Western Australia. The chapter successfully problematizes neat distinctions between embedded 
and specialist creative categories and points to the complexities of the lived experiences of creative workers. There are complex and highly individual intersections and complementarities between specialist, embedded, support and 'non-creative' work within the careers of the creatives studied. Based on their findings, the authors argue that innovative and enriched creative practice is based in a much more diverse range of activities and experiences than previously acknowledged in the literature. The findings suggest that enriched practice often emerges from a multiplicity of creative and non-creative activities within and beyond the creative sector. Self-identification as a creative worker, self-organization of the portfolio career and personal meaning-making are all important underpinnings to the construction of creative work.

\section{Part III Education, Learning and Careers}

The first chapter of Part III (Chapter 11) is a theoretical contribution that examines creative learning that takes place outside the formal education system. Such learning is not only of relevance to individual careers, but is equally important for the constitution of knowledge required to solve dynamic creative problems in many industry sectors. Although this type of learning has been studied extensively across many hi-tech and R\&D contexts, few studies exist that specifically examine learning in Creative Services teams. These teams must become adept at routinely producing original and imaginative ideas that solve problems with quite fixed requirements from clients. Greg Hearn, José H.P. Rodrigues and Ruth Bridgstock theorize what might influence learning processes in teams composed of Creative Services occupations as identified in the current volume. They suggest that complex system theories can be applied to understand both learning about each individual problem brief (Type 1 Learning) and the process of learning to survive over the long term by cultivating creative assets and resources in the team (Type 2 Learning). In Type 1 Learning different kinds of creative outcomes are involved, ranging from aesthetic variation to business paradigm innovation. Further, they propose that quite different types of learning are required for generative, evaluative and optimization tasks. In Type 2 Learning, capability acquisition is the objective. This is enacted in a large and very dynamic social network milieu, comprising competitive and collaborative processes. Teams may survive by adaptation or by merging with other agents, scaling up through replication of solutions or operating methodologies, or by gaining competitive advantage through first-principles innovation.

Next, Aneta Podkalicka (Chapter 12) considers the benefit of creative education to a different cohort - marginalized youth. She examines the 
Youthworx Media project, which provided accredited courses in Creative Industries alongside open-access multimedia workshops and independent one-on-one mentoring to young people in Melbourne, Australia. The chapter intersects with debates on non-linear youth transitions into education and employment (Furlong 2009; Fouad and Bynner 2008), and the role of creative production as an alternative educational site for skill development (Buckingham 2007; Sefton-Green and Nixon 2009). The aims of the students going into the course are considered, along with their postcourse outcomes and the benefits that they obtained from Youthworx. The disparity between stated dream jobs and interest in media employment, on the one hand, and future education and employment plans, on the other, perhaps demonstrates recognition of the precarity of creative employment. Podkalicka shows that Youthworx enables students to engage in further education in the Creative Industries or in other fields, and to increase their confidence and general employment-related skills to seek work elsewhere. This speaks to the broader applicability of Creative Industries education and demonstrates how such education can contribute to the broader economy and social engagement, thus embedding creatives beyond the Creative Trident modes of employment.

Chapter 13, 'Developing agency in the creative career', by Oksana Zelenko and Ruth Bridgstock, breaks new theoretical ground by introducing a design-influenced pedagogy for creative internships. Such workintegrated learning experiences are aimed at developing in undergraduate Creative Industries practitioners the skills to navigate disciplinary boundaries and manage their emerging professional identities in response to an uncertain, dynamic and rapidly changing world of creative work. A new conceptual framework for work-integrated learning (WIL) is presented, based in principles of design practice, that affords the development of necessary agency, autonomy and reflective capacity for professional success through student co-design of the learning experience. The chapter includes a case study of an advanced-level undergraduate WIL course. The content of reflective blogs written by WIL students from four creative disciplines is used to document students' experiences in designing/shaping their embedded and specialist professional roles and identities.

Education for portfolio careers is one of the themes canvassed in the last chapter in the book (Chapter 14), 'Graduate careers in journalism, media and communications within and outside the sector: early career outcomes, trajectories and capabilities'. In this chapter, Ruth Bridgstock and Stewart Cunningham report findings from a tracking study of ten years of graduates from Queensland University of Technology's courses in journalism, media and communication studies. The study describes the graduates' employment outcomes, characterizes their early career movements into 
and out of embedded and specialist employment, and compares the skill requirements and degree of course relevance reported by graduates employed in the different Creative Trident segments. The chapter engages with broader creative labour precarity discussions, and also ongoing assertions of graduate oversupply. The authors conclude by considering how university programs can best engage with the task of educating students for a surprisingly diverse range of media and communication-related occupational outcomes within and outside the Creative Industries.

This book is intended as a summation of the program of research conducted in the CCI within the Creative Workforce Program. As such, the contributions have been deliberately chosen from collaborators within CCI's network. The main aim of the book has been to document the research undertaken within CCI. We believe that the significance of this work is two-fold. First, we showcase the substantial work that has been undertaken by CCI to build a robust, international, empirical foundation, using national occupational data, from which to interrogate many contemporary debates, build new theory and formulate practical policy interventions. Second, we believe that the focus on creative work outside the Creative Industries has demonstrated how significant a gap there is in current understandings of creative labour, both in terms of sheer numbers as well as in the sample of theoretically relevant contexts and conditions. However, we do not claim in any way to have produced a definitive account, nor spoken the final word on these matters, and we look forward to future engagement with researchers outside our immediate collaborators.

\section{REFERENCES}

Andrews, G., Yeabsley, J. and Higgs, P. (2009), The Creative Sector in New Zealand - Mapping and Economic Role, Wellington: New Zealand Trade \& Enterprise, available at http://eprints.qut.edu.au/31133/ (accessed 29 July 2013).

Bakhshi, H., Hargreaves, I. and Mateos-Garcia, J. (2013), A Manifesto for the Creative Industries, London: Nesta.

Ball, L., Pollard, E. and Stanley, N. (2010), Creative Graduates, Creative Futures, London: Creative Graduates Creative Futures Higher Education Partnership and the Institute for Employment Studies.

Banks, M. (2010), 'Craft labour and creative industries', International Journal of Cultural Policy, 16 (3), 305-21.

Bridgstock, R. and Hearn, G. (2012), 'A conceptual model of capability learning for the 21 st century knowledge economy', in D.J. Rooney, 
G. Hearn and T. Kastelle (eds), Handbook on the Knowledge Economy, Volume Two, Cheltenham, UK and Northampton, MA, USA: Edward Elgar, pp. 105-22.

Bridgstock, R. (2013a), 'Not a dirty word: arts entrepreneurship and higher education', Arts and Humanities in Higher Education, 12 (2-3), 122-37.

Bridgstock, R. (2013b), 'Professional capabilities for twenty-first century creative careers: lessons from outstandingly successful Australian artists and designers', International Journal of Art \& Design Education, 32 (2), 176-89.

Buckingham, D. (2007), Beyond Technology: Children's Learning in an Age of Digital Culture, Cambridge: Polity.

Caroleo, F.E. and Pastore, F. (2011), 'Talking about the Pigou Paradox: socioeducational background and educational outcomes of AlmaLaurea', IZA Discussion Papers 6021, Institute for the Study of Labor (IZA).

Creative \& Cultural Skills (2010), Sector Skills Agreement for the Creative and Cultural Industries: An Analysis of the Skills Needs of the Creative and Cultural Industries in England, London: Creative \& Cultural Skills.

Christopherson, S. (2008), 'Beyond the self-expressive creative worker', Theory, Culture \& Society, 25 (7-8), 73-95.

Cunningham, S. (2011), 'Developments in measuring the "creative" workforce', Cultural Trends, 20 (1), 25-40.

Cunningham, S. (2013), Hidden Innovation: Policy, Industry and the Creative Sector, St Lucia, Queensland: University of Queensland Press and Lexington Books, an imprint of Rowman \& Littlefield.

Cunningham, S. and Higgs, P. (2009), 'Measuring creative employment: implications for innovation policy', Innovation: Management, Policy and Practice, 11 (2), 190-200.

De Peuter, G. (2011), 'Creative economy and labor precarity: a congested convergence', Journal of Communication Inquiry, 35 (4), 417-25.

Dell'Era, C., Buganza, T., Fecchio, C. and Verganti, R. (2011), 'Language brokering: stimulating creativity during the concept development phase', Creativity and Innovation Management, 20 (1), 36-48.

du Bois-Reymond, M. (2004), 'Youth - learning - Europe: Ménage à trois?', Nordic Journal of Youth Research, 12 (3), 187-204.

Florida, R. (2002), The Rise of the Creative Class: And How It's Transforming Work, Leisure, Community and Everyday Life, New York: Basic Books.

Fouad, N.A. and Bynner, J. (2008), 'Work transitions', American Psychologist, 63 (4), 241-51.

Furlong, A. (2009), 'Revisiting transitional metaphors: reproducing inequalities under the conditions of late modernity', Journal of Education and Work, 22 (5), 343-53.

Galloway, S., Lindley, R., Davies, R. and Scheibl, F. (2002), A Balancing Act: Artists' Labour Markets and the Tax and Benefit Systems, London: The Arts Council of England.

Gill, R. and Pratt, A.C. (2008), 'In the social factory? Immaterial labour, precariousness and cultural work', Theory, Culture \& Society, 25 (7-8), 1-30.

Granovetter, M. (2005), 'The impact of social structure on economic outcomes', Journal of Economic Perspectives, 19 (1), 33-50.

Hardt, M. and Negri, A. (2000), Empire, Cambridge, MA: Harvard University Press.

Haukka, S. (2011), 'Education-to-work transitions of aspiring creatives', Cultural Trends, 20 (1), 41-64. 
Haukka, S., Brow, J., Hearn, G. and Cunningham, S. (2010), 60Sox Report Volume 2: From Education to Work in Australia's Creative Digital Industries: Comparing the Opinions and Practices of Employers and Aspiring Creatives, Brisbane: Australian Research Council.

Hearn, G. and Bridgstock, R. (2010), 'Education for the creative economy: innovation, transdisciplinarity, and networks', in D. Araya and M.A. Peters (eds), Education in the Creative Economy: Knowledge and Learning in the Age of Innovation, New York: Peter Lang, pp. 93-116.

Hearn, G. and Bridgstock, R. (2014), 'The curious case of the embedded creative: managing creative work outside the creative industries', in S. Cummings and C. Bilton (eds), Handbook of Management and Creativity, Cheltenham, UK and Northampton, MA, USA: Edward Elgar.

Hearn, G. and Rooney, D. (2008), Knowledge Policy: Challenges for the 21st Century, Cheltenham, UK and Northampton, MA, USA: Edward Elgar.

Hesmondhalgh, D. and Baker, S. (2011), Creative Labour: Media Work in Three Cultural Industries, London: Routledge.

Higgs, P. and Freebody, S.P. (2010), Auckland's Creative Workforce Report 2010, Auckland: Auckland Tourism, Events and Economic Development Ltd.

Higgs, P., Cunningham, S. and Bahkshi. H. (2008), Beyond the Creative Industries: Mapping the Creative Economy in the United Kingdom, London: NESTA.

Howkins, J. (2001), The Creative Economy, Harmondsworth: Penguin.

Lash, S. and Urry, J. (1994), Economies of Signs and Space, London: Sage.

Leadbeater, C. (1999), Living on Thin Air: The New Economy, Harmondsworth: Penguin.

Mayer, V. (2011), Below the Line: Producers and Production Studies in the New Television Economy, Durham, NC: Duke University Press.

Menger, P.-M. (2006), 'Artistic labour markets: contingent work, excess supply and occupational risk management', in V.A. Ginsburg and D. Throsby (eds), Handbook of the Economics of Art and Culture (Vol. 1), Oxford: Elsevier, pp. 765-811.

MKW (2001), Exploitation and Development of the Job Potential in the Cultural Sector in the Age of Digitalization, Munich: MKW Wirtschaftsforschung $\mathrm{GmbH}$.

Mudambi, R. (2008), 'Location, control, and innovation in knowledge-intensive industries', Journal of Economic Geography, 8 (5), 699-725.

Neilson, B. and Rossiter, N. (2008), 'Precarity as a political concept, or, Fordism as exception', Theory, Culture \& Society, 25 (7), 51-72.

Pagan, J., Higgs, P. and Cunningham, S. (2008), Getting Creative in Healthcare: The Contribution of Creative Activities to Australian Healthcare, Brisbane: Australian Research Council Centre of Excellence for Creative Industries and Innovation.

Pang, L. (2009), 'The labor factor in the creative economy: a Marxist reading', Social Text, 27 (299), 55-76.

Potts, J. and Cunningham, S. (2008), 'Four models of the creative industries', International Journal of Cultural Policy, 14 (3), 233-47.

Potts, J., Cunningham, S., Hartley, J. and Ormerod, P. (2008), 'Social network markets: a new definition of the creative industries', Journal of Cultural Economics, 32 (3), 167-85.

Ross, A. (2008), 'The new geography of work: power to the precarious?', Theory, Culture \& Society, 25 (7-8), 31-49. 
Sefton-Green, J. and Nixon, H. (2009), 'Reviewing approaches and perspectives on "digital literacy", Pedagogies: An International Journal, 4 (2), 107-25.

Stoneman, P. (2010), Soft Innovation: Economics, Design, and the Creative Industries, Oxford: Oxford University Press. 
Greg Hearn, Ruth Bridgstock, Ben Goldsmith, and Jess Rodgers - 9781782545705 Downloaded from PubFactory at 04/26/2023 08:58:01AM 